INTERNATIONAL JOURNAL OF RESEARCHES IN BIOSCIENCES, AGRICULTURE AND TECHNOLOGY (c) VISHWASHANTI MULTIPURPOSE SOCIETY (Global Peace Multipurpose Society) R. No. MH-659/13(N) www.vmsindia.org

\title{
FASHION TRENDS AND ITS IMPACT ON SOCIETY: A CASE STUDY ON APPAREL TRENDS OF INDIAN SOCIETY
}

\author{
Barkha Ravi Shende \\ Gandhigram College, Wardha (MH), P-35, Barbdi Road, M.I.D.C.,Wardha-44200 1 \\ Email id: barkha.shende1718@gmail.com
}

\begin{abstract}
:
India is a multidimensional country comprising 1.27 billion population spread ove $\mathrm{r}$ various regions having diffe rent tradition and rituals though the basic culture re mains the same. Due to this lot of special costumes and appare 1 are be ing obse rved which has a long history. It is our commitment to take the se renowned Indian traditional cos tumes, having long cultural continuity, globally.

Every trend has its roots somewhere in history and trends are really what fashion world go round. Innovations \& Renovations is a big wave that is currently in vogue. It can be anything, right from the Retro style 'Bell Bottoms', Bobby prints, smart textiles, Sadhana cut, Size zero and body modulation such as tattooing, pie rcing or surgeries. We all know "It is costume which establishes the individual's identity in society" and the re fore kee ping my scope of study limited to the apparel trends and its impact which has ins pirations from our history which goes back to $4000-$ 5000 BC. Right from Indus valley civilization followed by Maurya, Sunga, Satvahan, Kus han, Gupta, Mughal\& British these periods showed the identifying fashion trends. Even afte $r$ the strong Impact of the Britishers, we Indians have ke pt our tradition perpetual and carried forward, but the ongoing and upcoming western trends are engulfing our Indian society at large. Thus, our inner Indian culture is getting blurred and we should now be worried as it would be on the verge of extinction with time. But as we know, our Indian culture souls will always stay evergreen. It can never die. Our offspring's will only see the left over India's culture in museums. We need to promote our cultural he ritage so that this superficial layers of other cultures vanishes and bring out our Indian culture and trends on to world platform to kee $p$ this country's treasure alive i.e. culture
\end{abstract}

Ke ywords: Apparel trend, History of fashion, Indian costume, Indian culture, Impact in future.

Today's Fashion, that has always been a multidimensional universal impact, is not just a change, a tre nd but the spirit of the times, the succession and combination of styles. It is not just a relation among classes. Fashion is the most complete expression of a post-modern industrial culture that finds its way to be in the design process. (FIORANI, 2006, p. 7)

\section{Introduction:}

"Fashion is not something what exists in dresses only. Fashion is in the sky, in the street; fashion has to do with ideas, the way we live, what is happening."

\section{Coco Channel, 1883-1971}

From a crawling baby of some months old to a white hair, teeth broken lady every single individual has their own fashion statement. Fashion is endless and is been around since beginning of human race. "Fashion is the mold of the contemporary, in its ability to join in the dynamics between the individual and society" [FIORANI, 2006]

Fashion is something we deal with everyday. One can find a lot of changes and evolution in the history of fashion. Fashion can affect the economy of a country or the whole world. It can sway politics, serve as an art form and can affect someone's personal life. Needless to say, fashion is arguably being one of the biggest factors that affect and that can be affected by the socie ty. It has always been present and will be present for as long as human race exists.

Trends are really what the fashion world go round- a new trend catches on, designers make their own versions, the public buys the se products, the tre nd fades and a new trend emerges. Trends has a large broad spectrum which includes various fields such as; clothing, footwear, accessories, makeup, body piercing, tattooing, plastic surgeries, Interior Design or furniture. Apparel sector India is estimated to grow to $\$ 220$ billion by 2020 and the refore Apparel trends are more famous than any other. We can see many types of new tre nds in apparels. Some example of tre nds :- Retro style Bell Bottoms, Bobby print, Chiffon sarees, Anarkali's suits, Mumtaz saree, velvet garme nts, skinny pants and so on......

The Society is a community of people living in a country or region and having shared customs, laws and organization. In our society the re are various classes and they having their different way of dressing and life style. We need to keep in consideration every class of people while speaking about society. The garment we wear depicts our personality. There are positive as well as negative impacts on our society. The new innovations and talent of our new ge neration and designers is worth complimenting. They have given new name to the Indian trends internationally. On the other hand the new trends are projecting a wrong picture in minds of 
the people, especially with girls, skirts are ge tting shorter and the neck line on shirts has dropped. India's heritage and tradition getting lost somewhere due to the new kids. Very few teens are left who still prefers the Indian apparels in functions rather than the LBD and that LITTLE will soon become TINY. All these are under the grab of freedom of expression and women empowerment.

\section{Objectives of Study:}

- Study the new fashion trends in India.

- Examining the emerging trends in appare 1 sector in India.

- Understanding the apparel trends of ancient India.

- Analyzing the challenges faced by the society due to fashion trends and its impact in India.

- To think on the degree of influence on later generation due to coming up fashion tre nds in India.

\section{Factors that Affect Fashion and sets the} trends

'Nothing is constant except for change!' Fas hion is nothing but a constantly changing tre nd. This term is associated with clothes and accessorie s majority of the times. People relate fashion to what they wear. Though fashion is a wider concept, it has narrowed down to fabric, apparel, and accessories in modern times. The following factors affects / influe nces the Trends

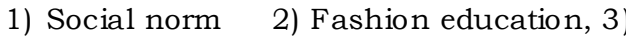
Mass media, 4) Peer groups, 5) Social criticism 6) Environment 7) Customs, traditions, 8) Religion, 9) Work, 10) Leisure activities 11) Wealth or change in income, Inspiration by friends,

13) Changing trends and Values,

14) Influe nce by family members,

Education, 16) Age

However, there is limited literature on fashion trends of India and little emphasis is placed on the impacts of these trends on society on the above parameters. Parul Bhatnagar (2012) professed in her book traditional Indian costumes and textiles that, it is "Costume" which establis hes his / her individual identity in society and which also links up with social hierarchy. According to Anamika Pathak (2008) Indian costume is outcome of nearly four thousand ye ars of his tory w rou ght with significant political, economic, social and cultural upheavals and influences. The costumes which form an integral part of any historical dominant culture in India also underwe nt se veral crucial transformations. According to Usha Kulshreastha and Radha Kashyap, Clothes help to make us self- confident, jolly, free, or they make us self-conscious, shy, sensitive and restrained. They determine how much we go into society, the places we go to, exe rcise we take. Sharon Lee Tate in book Inside Fashion Design says that inevitably, constant exposure to differentcultures and the way people interpret fashions around the world influences fashion tre nds.

To understand the present scenario of fashion apparel trends in India and their impacts in context of the history of clothing, de scriptive and case study approach has been the re in the study to reveal the degree of impact on future. This research consists of application of secondary data. The secondary data has been colle cted from the reports, journal, previous studies, books, websites etc.

\section{Evolution of Fashion:}

The Indian village bears little resemblance to its predecessor of about six thousand years ago. For centuries, Indian Costumes and Textiles have been admired for their great aesthetics and cultural values. Clothes are natural to human and their proper decoration on his unclothed body is not ugly, on the contrary it is beautiful and pleasing. Costumes are used not only to cover the body and embellish it; they also constitute a significant non-verbal medium of communication that serves to establish the cultural identity of a person's community or country of origin at any given historical period. They help understand fashion trends prevalent during historical time-frame. It has been observed that fashion trends usually veer towards new direction every te $n$ to twenty years.

Indian Costumes from the earlier times to the beginning of historical period:

His tory testifies that man has throughout been investigating and creating for their need fulfillment. It is, therefore that his essential love of nature has been manifest dire ctly or indire ctly in all such creation. His needs, his sociogeographical environment, his economic status are fully represented therein. Particularly, among the costumes show the utmost influence of the social life, the seasons and his field of work. The his to rical continuity of fashion can be a guide in the prediction of fashion trends (Sproles, 1981). Three main sources - archeological evidence, literary references and actual costumes- furnish crucial leads in the reconstruction of the history of Indian costumes. The archeological history of Indian textiles starts from the Indus Civilization (4000 BC). followed by Budha period ,The Maurya and Sunga Periods (c. 324-72 BC), The Satvahan Period (c. 200BC-AD 250), The Kushan Period (c. $130 \mathrm{BC}-\mathrm{AD}$ 185), The Gupta Period (c. AD $4^{\text {th }}-5^{\text {th }}$ 
Centuries), The Mughal Period (16 th-19th Centuries).

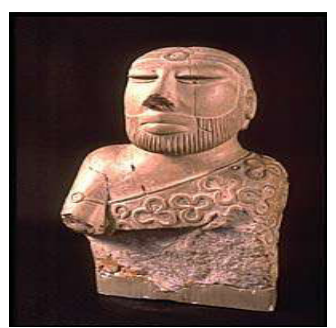

Figure 1: Excavated bust of Priest-King Indus Valle y Civilization

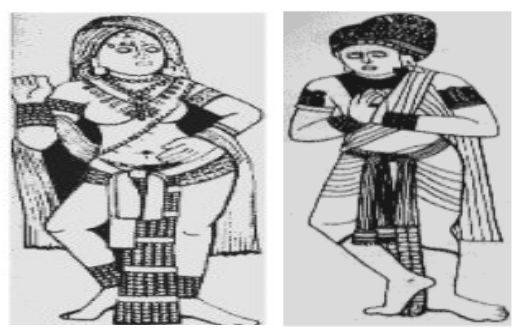

Figure 2: the Maurya Sunga Period $371 \mathrm{BCE}$ to 72 BC Fig -2 , the Maurya Sunga Period $371 \mathrm{BCE}$ to $72 \mathrm{BC}$
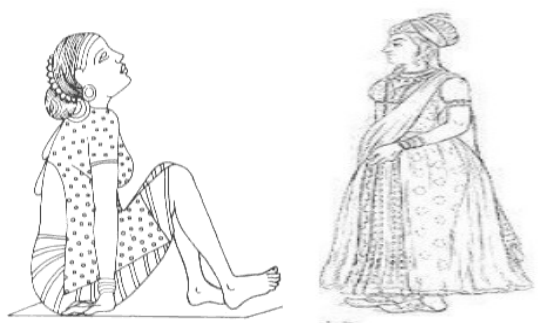

Figure 3 The Kushan Period (c. 130 BC-AD 185): Impact on Clothing:

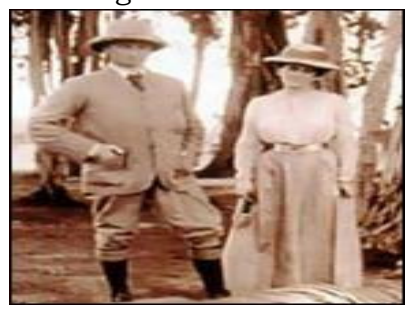

Figure 4: Gupta Pe riod 4th to 8th Century AD Indian Fabrics were treated as exotic and the British fell in love with cotton and indigo. These Indian textiles influenced British tastes before the Raj. But once the British started ruling, everything changed, a new culture emerged and so did a new cultural ide ntity. There was a stark difference in the dressing sensibilities of the Britis $h$ and Indians.

After looking at the clothing attires of British people, Indians started looking down upon the mselves, they thought that their cus to ms and costumes reflected illiteracy and so refused to wear their native clothes. And here started the revolution, Indians tried to change the attires and follow up the Britishers.

"The process of imitation and adaptation are central to our understanding of creativity. Human cultures evolve through a continuous exchange of ideas, beliefs, habits and forms. Dressing habits in particular constitute a fertile plain in which this exchange takes place." (Artemis Yagou: 2009). Though tre nds came but the rise of a "westernized" society in India was a result of the mighty British taking over the reins of the country. The main impact was due to them. But this did not last for long.

\section{Today's Trend:}

Today, you can well describe our Indian clothing industry in a blossoming take off stage. Versatile Indian clothing styles reflects the faces of diversity in India. Apparels are undergoing astounding changes in this globalized era. Fashion often reflects the society. Important personalities in history have also had an impact on fashion, but no matter how competitive and innovative the Fas hion industry is, it actually has to follow what is called the "Fashion Cycle", which has no specific measurable time period. Some styles sustain for longer period of time. Some die out soon, and some styles come back ye ars after they we re declined. So we can say that fashion changes with time and has always been evolving to fit the taste, life style and demands of society. Every new day comes with a new tre nd. Today every next person has their own different and unique choice of dressing, some loves to dress in more peppy and tre ndy way so some love the casual sense, the other one way is skater or shaggy while the few goes gothic and baggy clothing. Still we get population today who likes Indian costume and dresses. My main focus is on the newer generation. As the taste changes the same way trends comes in all such kinds of apparels.

Indian designers have already marked their prominent places in fashion market. Exotic designs developed by designers have created a great impact on uplifting Indian clothing tre nd in world. These designs have increased the acceptability of Indian clothing in the international textile market. Today INDOWESTERN FUSION which gives a contemporary look is highly demanded garments across the world. As time goes, Indian clothing trend continues as an evolving subject.

Smart textiles are heading the ir way when we talk about the recent trends and future of clothing. Smart textiles are the fabrics that have been developed with the technologies that provide added value to the wearer. From flying dresses, 
self illuminating textiles to the dresses which can protect elde rly from fractures and also with antiageing properties.

Some of the trends in apparels are: ripped denims, off-shoulder one pieces, bra tops, Neon funky T-s hirt, wome n colorful coats, formal skirts, trousers, floral pants, jumpsuits, kaftan/poncho shirt, tu nics, LBD, shrugs, hare m pants, palazzo etc. "Leggings seen as a fashion forward statement in the 80 s is now a universal trend that has become mainstream fashion and this versatile fashions are the fashion world's latest obsession (Apparel Online, 2011).

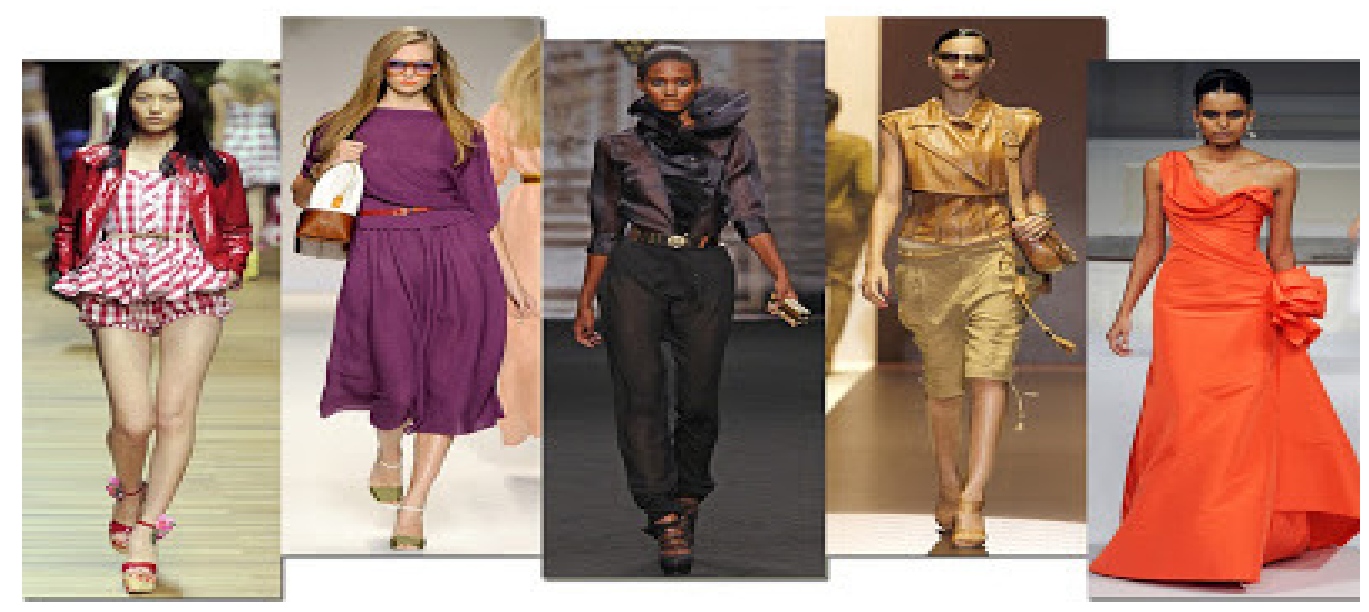

Figure -7 Diversity in Fas hion

\section{Recent Trends}

The survey analysis shows that the fashion trends are expecting 20-30\% growth in next 5 years and therefore the trend which will be coming is at larger scale and can influence a larger population. So now the question and excitement is which trend will be coming?

\section{Impact on Society:}

We can argue whe ther or not the fashion trends has more of a positive or negative effect on people of today, regardless we can agree that the apparel industry has grown to become very popular and influential. Socie ty comprises of the population including infants, small kids, teens, adults, working population, and retired people. There are various categories including different level of population and their mindsets, so the influence or impact of the tre nds will diffe $r$ from category to category, group to group, and individual to individual. Fashion is always rapidly changing for a reason.

The age when the impact of anything is at peak is between 10-24 because at this age we don't develop to use our mind and differentiate between what is actually good and bad. According to a research more than half $55 \%$ of the urban youth in India keeps a close track of latest trends of life style, clothing etc.

As there are two sides of coin, in the same way there can be positive as well as negative impact of fashion trends on society. Some impacts are given below:

\section{POSITIVE IMPACT:}

- New ideas, designs and trendy look in invented.

- Apparel industry gives chance to designers to express their talent.

- There are unending opportunities in Apparel sector. The possibilities are truly endless.

- The new fashion comes and gives a branded modern look to any ord inary man.

- People stay fashionable and stylish to attract the opposite sex to get noticed by someone they like. With the help of fashion you can look the part and get acknowled ge.

- The world is huge, filled with many diversity and cultures. Fashion and apparels is like one language that everyone can understand. It connects people internationally because fashion travels from one city to the next.

- Fashion is the ultimate way to express oneself. One of the first impression people have of you is from your appearance.

- Fashion and tre nds and that to apparel are one of the most popular items and one of the most popular topics spoken on television, magazines, and internets. With their popularity they can influence many people.

\section{NEGATIVE IMPACT:}

- Bending generation towards western culture.

- Forgetting Indian culture and ethnics.

- Showing more interest in the Hollywood fashion and trends than own country.

- Today's new generation prefer western outfits than traditional. 
- Many people not only follow the latest trends and styles but also believe and emulate the images of sticky skinny that are projected by fashion industry.

- Young girls do to achieve such zero figure images and then lead to dangerous eating disorder, mental health issues, Anorexia, body mutilation and even suicides.

- The attractive ads of the apparels and new trends telling what's hot and what's not engulfs the teens.

- The use of really thin and unhealthy models for the apparels show.

- The ways that today's teenagers and young adults are wearing the trends of the 1960's (my parent's decade) are more scandalous and revealing.

- The global scenario in the economic perspective is yet another influe nce that has altered Indian Fashion.

The percent share of consumption Apparels in this year, 2015 will be $100 \%=$ US $\$ 40 \mathrm{bn}$. This surely indicates the importance and de mand and use of apparels and so to ensure the future, we need to take so major and frequent steps. Although all the designers are already working hard to create new innovation in the traditional costume but what our today's socie ty want is just modern and western look.

\section{Impact in Future:}

Indian clothing style have conquered fashion textile across the globe but the Indian themselves are unaware of the treasure they have gained. Indian fashion has transformed through years, harne ssing both the traditional and cosmopolitan look. The wes te rn influence is so strong on Indian culture that it has paved the way for a difference in style. The future of fashion will be very diffe rent from its past. Globalization, and the accessibility of cultures, and the interconnectedness of people over the internet and through mass media will likely force a convergence of fashion trends in architecture, music, online presence, and clothes.

\section{Suggestion:}

Fashion has truly become a se rious business in India (Textile Trends, 2010). I think the trends should be made keeping our Indian culture in mind. We should not blindly follow the trends coming in India. The International brands entering the Indian market, let them come but it is us who can carry our tradition forward. Thanks to Hon. PM Narendra Modi for "MAKE IN INDIA" concept for which we can also give our small contribution.
- Use of 'made in India' apparels.

- Increase in employment by designing dresses as Indian embroidery works have gained popularity all over world and so we can prefer hand e mbroidery.

- We can bring a lot and beautiful trends in our Indian costume, and such looks can even be accepted by youths as they want only change and nothing else.

- At least wear traditional costumes in the festivals and rituals so that it can be carried forward and be known by the coming generation

\section{Conclusion:}

The main aim was just to understand how the apparel trend can impact us. The noticeable changes in trends were seen from centuries but still our ancestors kept the Indian treasure alive even after the strong influence of Britishers. But now the new fashion trends and the western culture influence are more effectual which is not only changing the clothing's but also the minds of generations. While Indian youth was adopting western trends, the West was getting highly influenced by Indian culture and practices.

Today's society wants to get modern but that doesn't mean you go western. Indian fashion today is about change, price, brand, confidence and position.

All we can conclude is that it finally depends on you. The beauty of you lies in yourself and not in the trends. So you decide? You want to get influence by other trends or create your own trend and influe nce others.

"Don't be into tre nds. Don't make fashion own you, but you decide what you are, what you want to express by the way you d ress and the way to live." - Gianni Versace.

\section{References:}

\section{Books:}

Bhatnagar , P (2009).Traditional Indian Costumes and Textiles. Chandigarh: Abhishek Publications

Kulshrestha , U ., Kashyap , R (2007) Clothing behavior. Jaipur: Pointer Publishers.

Pathak , A . (2008) Indian Costume. Luster Press, Roli books.

McClaud , P (2013) Past and Pre sent Trends in Fashion Technology. Chandigarh: Abhishek Publications

Research papers:

OZIPEK , B., TANYAS , M., \& MAHMUTOGLU DINC , N. (2012). FACTORS AFFECTING BRANDING WITH SPECIAL REFERENCE TO CLOTHING INDUSTRY. Paper presented at RMUTP International Conference: Textiles \& Fashion 2012 July 3-4, 2012, Bangkok Thailand 
Singh , J ., Gupta , K. (2014). Bollywood and Fashion Trends in India: A Longitudinal Study.Pape r presented at International Journal of scientific research and management (IJSRM)

Pani , A., Sharma , M .(2012). A Case Study of Ap parel Retailing in India .

Israsena Na Ayudhya, P.,(2007).Emerging Trends In Tre nd Re search

Desai , H.,(2011).Module: Sociology Of Design Assignment 2: Redefining Indian identity through fashion.( Ethnic Vintage)
Lam , A ,.(2009). Western influence on Bollywood Gupta , T ,.(2011). The Effe ct of the British Raj on Indian Costume

Vagasi-Kovacs , A,.(2012). Fashion Trend Revival - Fashionable cultural heritage.

Design research in Fashion:from trends to design directions, Chiara Colombi

\section{WEBSITES:}

http:/ / fashio nalldayerrday.blogspot.com/2012/05/10-positive-effects-of-fas hion-indus try.html http:/ / www.studymode.com/essays /Positives-And-Negative-Effects-Of-The-66146179.html http:/ / women-world wide.blogspot.com/2014/09/fas hion-indus try-and-wo men-empowerment.htm1 http:/ /www.academia.edu/2133441/The_Influence_of_British_Raj_on_Indian_Fashion http:/ / process .arts.ac.uk/sites /de fault/ files / toolika-gupta-effect-of-british-raj-on-indiancostume.pdf

http:/ / fashionalldayerrday.blogspot.com/2012/05/10-positive-effects-of-fas hion-indus try.html www.brainyquote.com/quotes/quotes/c/cocochane14025

www.co cochanelquotes.org/fashion-is-not-something

chanelcollections .wordpress.com

www.pbs.org/newshour/extra/1999/10/what-is-fashion.

sheelooba.blogspot.com

http:/ / britishlibrary .typepad.co.uk/inspiredby/2013 / 05 /a-be ginners-gu ide-to-fashion-trendforecasting.html\#s thash.ax4EGyvk.d puf

( http://kaitlincopp.wordpress.com/)

http:/ /indiatoday.into day.in/story/bollywood-influence-on-fashion-trends / 1/230516.html

Oxford Dictionary 